\title{
Abiotic Stress and Induced DNA Hypomethylation Cause Interphase Chromatin Structural Changes in Rice rDNA Loci
}

\section{(C) Free Author Copy - for per- sonal use only} ANY DISTRIBUTION OF THIS ARTICLE WITHOUT WRITTEN CONSENT FROM S. KARGER AG, BASEL IS A VIOLATION OF THE COPYRIGHT.

Written permission to distribute the PDF will be granted against payment of a permission fee, which is based on the number of accesses required. Please contact permission@karger.ch

\section{Key Words}

Abiotic stress - 5-Azacytidine - Chromatin organization • rDNA $\cdot$ Rice typically with circular arrangement around the nucleolus. The results suggest a role for chromatin plasticity in a world of climate changes.

Copyright $\odot 2011$ S. Karger AG, Basel

\begin{abstract}
Global climate change, i.e. higher and more variable temperatures, and a gain in soil salinity are increasing plant stress with direct consequences on crop yield and quality levels. Rice productivity is strongly affected by abiotic stress conditions. The regulation of chromatin structure in response to environmental stress is poorly understood. We investigated the interphase chromatin organization from rice plants in non-stress versus stress conditions. We have used a cytogenetic approach, based on fluorescence in situ hybridization (FISH) with 45S, 55 rDNA and centromeric probes on rice tissue sections. The abiotic stress conditions included cold, heat and mild salinity and were applied during seed germination. In contrast to cold, saline and heat stresses caused extensive decondensation of $45 \mathrm{~S}$ rDNA chromatin and also an increase in the distance between the 2 homologous 55 rDNA loci. 5-Azacytidine (5-AC), a DNA hypomethylating drug, greatly increased $45 \mathrm{~S}$ rDNA chromatin decondensation and interestingly was able to induce polarization of centromeres in rice interphase nuclei. The abiotic stresses tested did not perturb the spatial position of centromeres,
\end{abstract}

Genomes are constantly subjected to stress; for example, plants are constantly coping with stressful environmental conditions, e.g. cold, heat or high salinity soil, all of which seriously affect plant growth. Little is known regarding the effect of abiotic stress on chromatin organization [reviewed in Arnholdt-Schmitt, 2004; Kim et al., 2010]. McClintock [1984] predicted that stress can cause large-scale genomic changes including transposon activation and other structural modifications of chromosomes. Madlung and Comai [2004] proposed a model to explain genome regulation under normal and stress conditions, suggesting that under normal conditions, heterochromatin maintenance mechanisms repress transcription of repetitive DNA and that stress leads to relaxation of epigenetic marks and altered gene expression. Some studies have pointed out a link between environmental signals, chromatin conformation and epigenetic changes [e.g. reviewed in Chinnusamy and Zhu, 2009]. In Arabidopsis, a mutant analysis showed that the blue-light photoreceptor cytochrome 2 is involved in triggering chromatin decondensa-

\section{KARGER \\ Fax +4161306 1234 \\ E-Mail karger@karger.ch}

www.karger.com (c) 2011 S. Karger AG, Basel

$1424-8581 / 11 / 1324-0297 \$ 38.00 / 0$

Accessible online at:

www.karger.com/cgr
Ana Paula Santos

Genomics of Plant Stress Laboratory

Instituto de Tecnologia Química e Biológica

Quinta do Marquês, Av. da República, PT-2780-157 Oeiras (Portugal)

Tel. +351 21446 9644, Fax +351 21441 1277, E-Mail apsantos@itqb.unl.pt 
tion [Tessadori et al., 2007]. Also, the exposure to cold leads to chromatin changes at the FLC locus with reduction of acetylation at $\mathrm{H} 3 \mathrm{~K} 9$ and $\mathrm{H} 3 \mathrm{~K} 14$ sites, and increase in methylation of the H3K9 and H3K27 sites, corresponding to the formation of heterochromatin [Bastow et al., 2004]. The FLC locus also showed reduced H3K4 trimethylation, which has been associated with transcriptional activation after vernalization [Amasino, 2004].

Plants contain thousands of rDNA repeats which widely surpass the necessary number of genes to sustain ribosome synthesis [e.g. reviewed in Huang et al., 2006]. Only a subset of the rRNA genes is actively transcribed at any given time. For example, in pea only $5 \%$ of rDNA units is transcribed [Gonzalez-Melendi et al., 2001]. Hence, 2 contrasting types of chromatin structures may coexist: an 'open' one corresponding to transcriptionally active genes and a 'closed' one with heterochromatic configuration forming perinucleolar knobs representing the non-transcribed genes [Conconi et al., 1989]. Thus, ribosomal chromatin has been viewed as a good example to illustrate a link between chromatin states and gene activity [reviewed in McKeown and Shaw, 2009]. We have used a cytogenetic approach based on fluorescence in situ hybridization (FISH) to monitor changes in ribosomal chromatin structure and in the spatial disposition of centromeres in interphase nuclei after imposed abiotic stress or after induced DNA hypomethylation. For this study, we chose rice since its productivity and quality is seriously affected by abiotic factors (e.g. water scarcity, cold, and salinity). In contrast to cold stress, the saline and heat stresses caused extensive decondensation of $45 \mathrm{~S}$ rDNA ribosomal chromatin and an increase in the distance between the 2 homologous $5 \mathrm{~S}$ rDNA loci. The presence of 5-azacytidine (5-AC) during germination greatly increased ribosomal chromatin decondensation and caused polarization of centromeres in interphase nuclei. In contrast, the spatial position of centromeres in rice interphase nuclei, typically with circular arrangement around the nucleolus, was not significantly perturbed by any of the abiotic stress conditions tested. The results suggest a link between ribosomal chromatin plasticity and response to the challenges of abiotic stress.

\section{Material and Methods}

\section{Plant Material and Stress Treatments}

Seeds from diploid rice (Oryza sativa ssp. japonica, $2 \mathrm{n}=24$, cv. Nipponbare) were germinated for 3 days at $28^{\circ} \mathrm{C}$ on filter paper soaked either in water, in a solution of $150 \mathrm{~mm}$ sodium chloride (salinity stress) or in $80 \mu \mathrm{M} 5$-AC solution (Sigma) as described in
Santos et al. [2002]. The imposed thermal stresses consisted of cold $\left(4^{\circ} \mathrm{C}\right.$ for $\left.24 \mathrm{~h}\right)$ or heat $\left(42^{\circ} \mathrm{C}\right.$ for $\left.3 \mathrm{~h}\right)$ before harvesting roots. Root-tips were fixed in $4 \%(\mathrm{w} / \mathrm{v})$ formaldehyde freshly prepared from paraformaldehyde in PEM buffer (50 mM PIPES, KOH pH 6.9; 5 mM EGTA; $5 \mathrm{mM} \mathrm{MgSO}_{4}$ ) for $1 \mathrm{~h}$ at room temperature and then washed in TBS (10 mM Tris- $\mathrm{HCl}, \mathrm{pH} 7.4 ; 140 \mathrm{mM} \mathrm{NaCl})$ for $10 \mathrm{~min}$.

\section{Root Sectioning}

Root-tips were sectioned using a Vibratome Series 1000 (TAAB Laboratories Equipment Ltd., Aldermarston, UK) and allowed to dry on multi-well slides (Menzel-Glaser). The root tissue sections were approximately $20 \mu \mathrm{m}$ thick containing about 2 cell layers and showed a good preservation and integrity of tissue structure. The slides were pre-treated by washing in 3\% Decon for at least $1 \mathrm{~h}$, thorough rinsing with distilled water and coating with a freshly prepared solution of $2 \%(\mathrm{v} / \mathrm{v}) 3$-aminopropyltriethoxysilane (APTES, Sigma) in acetone for $10 \mathrm{~s}$ and activated with $2.5 \%$ (v/v) glutaraldehyde (Sigma) in PBS for $30 \mathrm{~min}$, rinsed in distilled water and air-dried. The tissue sections were dehydrated in a methanol series and then digested in an enzyme mixture of cellulase $1.5 \%(\mathrm{w} / \mathrm{v})$ (Onozuka R-10, Japan) and pectolyase $(0.5 \%$ (w/v) Sigma) in $1 \times$ EB (0.4 mM citric acid; $0.6 \mathrm{~mm}$ trisodium citrate, $\mathrm{pH} 4.8$ ) for $1 \mathrm{~h}$ at room temperature. Finally, the sections were washed in TBS for $10 \mathrm{~min}$, dehydrated in a methanol series and air-dried.

\section{FISH on Root Tissue Sections}

FISH was performed as described in Santos et al. [2002]. Briefly, the hybridization mixture contained $200 \mathrm{ng}$ of DNA probe, $50 \%$ deionized formamide, $20 \%$ dextran sulfate, $10 \% 20 \times$ SSC, $1.25 \%$ sodium dodecyl sulfate and $1 \mu \mathrm{g}$ of sonicated salmon sperm DNA as blocking DNA. The following plasmids were used as probes: $\mathrm{pRY} 18$, which carries a 3.8-kb DNA fragment containing the rice genomic $45 \mathrm{~S}$ rDNA cluster (includes the 3 ' half portion of $18 \mathrm{~S}$ rRNA gene, the complete $5.8 \mathrm{~S}$ rRNA gene and the $5^{\prime}$ half portion of $28 \mathrm{~S}$ rRNA gene); pRTY5S carrying a 3-kb DNA fragment that contains the rice $5 \mathrm{~S}$ rDNA (kindly provided by Prof. N. Ohmido); pRCS2 that contains rice centromeric specific $\mathrm{CentO}$ repeats [Dong et al., 1998], kindly provided by Prof. J. Jiang. Probes were labeled with digoxigenin-11-dUTP or biotin16-dUTP (Roche) by nick translation. The hybridization mixture was denatured at $95^{\circ} \mathrm{C}$ for $5 \mathrm{~min}$, cooled in ice for another $5 \mathrm{~min}$ and immediately applied to the sections. Target DNA denaturation was carried out in a modified thermocycler (Omnislide Hybaid Ltd) at $78^{\circ} \mathrm{C}$ for subsequent hybridization at $37^{\circ} \mathrm{C}$ overnight. Post-hybridization washes were performed using $20 \%$ formamide in $0.1 \times$ SSC at $42^{\circ} \mathrm{C}$. Probes were labeled with digoxigenin or biotin and detected with an anti-digoxigenin antibody conjugated to FITC (Boehringer Mannheim Corp.) or to extravidin-cy3 (Sigma), respectively. Both antibodies were diluted in $3 \%$ BSA in $4 \times$ SSC, $0.2 \%$ Tween- 20 (Sigma) and incubations were carried out in a humid chamber for $1 \mathrm{~h}$ at $37^{\circ} \mathrm{C}$ followed by $3 \times$ 5 min washes in $4 \times$ SSC, $0.2 \%$ Tween- 20 at room temperature. The sections were counterstained with $6 \mu \mathrm{g} / \mathrm{ml} 4^{\prime}, 6$-diamidino2-phenylindole (DAPI, Sigma) for $5 \mathrm{~min}$ and mounted in Vectashield antifade solution (Vector Laboratories Inc., Burlingame, Calif., USA). 
Table 1. Number and volume $( \pm S D)$ of heterochromatic knobs in distinct abiotic stress conditions

\begin{tabular}{llll}
\hline Treatment & $\begin{array}{l}\text { Cells } \\
\text { analyzed }\end{array}$ & $\begin{array}{l}\text { No. of heterochro- } \\
\text { matic knobs/cell }\end{array}$ & $\begin{array}{l}\text { Volume of heterochro- } \\
\text { matic knobs, } \mu \mathrm{m}^{3}\end{array}$ \\
\hline Control & 75 & $2.08(0.67)$ & $1.40(0.73)$ \\
Cold & 80 & $2.11(0.76)$ & $2.19(1.25)$ \\
Heat & 37 & $2.03(0.44)$ & $1.12(0.34)$ \\
$\mathrm{NaCl}$ & 80 & $2.09(0.90)$ & $0.99(0.42)$ \\
\hline
\end{tabular}

Confocal Fluorescence Microscopy, Image Acquisition and Analysis

Confocal optical section stacks were collected with a Leica TCS SP confocal microscope (Leica Heidelberg GmbH, Mannheim, Germany) equipped with a krypton and an argon laser. The microscopy data were recorded and then transferred to Image J and composite using Adobe Photoshop (Adobe Systems Inc., Mountain View, Calif., USA).

\section{Statistical Data Analysis}

Differences between treatments were evaluated with a nonparametric Analysis of Variance on Ranks (Kruskal-Wallis test) since the assumptions of the parametric ANOVA, namely normal distribution of data and homoscedasticity of treatment variances were not met. Otherwise data were analyzed with ANOVA. Posthoc comparisons between groups were made with the non-parametric mean rank comparisons after the non-parametric ANOVA used a priori to control for type I errors. Observations greater than 1.5 times the $3 r d$ quartile plus the interquartile range are considered as outliers. The co-localization of 5S rDNA and centromeres was evaluated with the Pearson $\chi^{2}$ test of independence. Significance was accepted for $\mathrm{p}<0.05$.

\section{Results}

\section{The 45S rDNA Chromatin Organization in}

Interphase Nuclei Consists of 2 Perinucleolar

\section{Heterochromatic Knobs}

The $45 \mathrm{~S}$ rDNA loci consist of tandem arrays of repeating units of the 18S, $5.8 \mathrm{~S}$ and $28 \mathrm{~S}$ rRNA genes and the transcribed and non-transcribed spacers, each unit being typically $10 \mathrm{~kb}$ long in plants. We performed FISH with the $45 \mathrm{~S}$ rDNA probe in interphase nuclei of meristematic cells from rice root tissue sections made on a vibratome. Tissue sections were approximately $20 \mu \mathrm{m}$ thick and showed good preservation and integrity of tissue structure. An entire rice root tip section in which the DNA is stained with DAPI is shown in figure 1A. The organization pattern of $45 \mathrm{~S}$ rDNA consisted mainly of 2 large and well-defined heterochromatic knobs at the periphery of

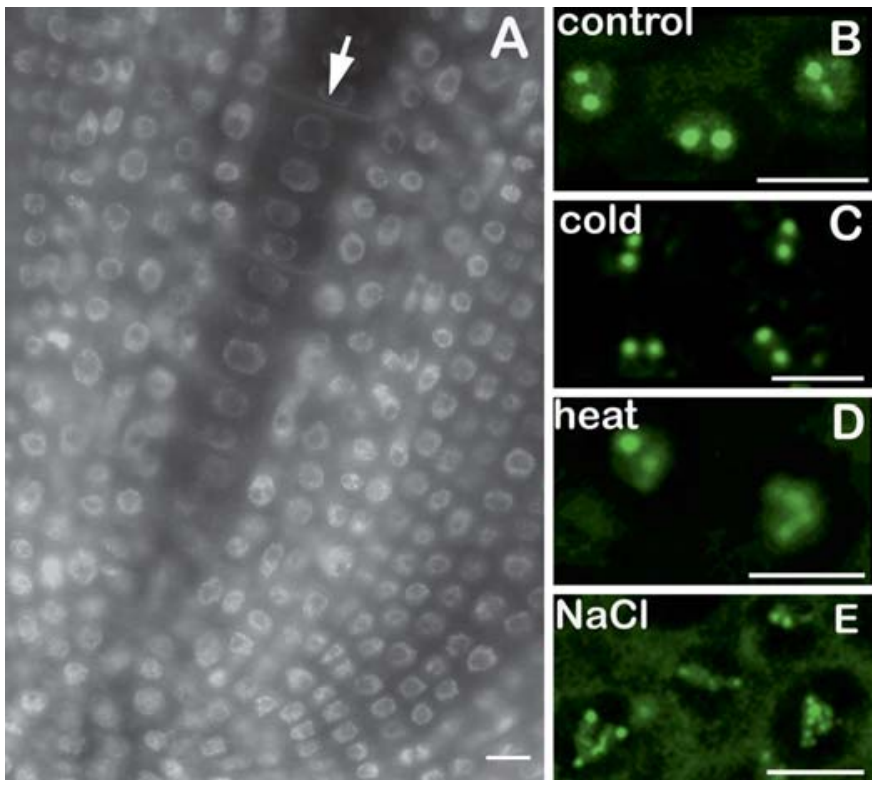

Fig. 1. Rice root tissue section labeled with DAPI, arrow indicates the xylem vessel precursor cells (A). 45S rDNA chromatin organization in 3D interphase nuclei of rice root sections after seed germination in water (B) or in the presence of abiotic stress conditions such as cold (C), heat (D), salinity (E). Note the 2 heterochromatic knobs at the nucleolar periphery, presumably inactive (A, B) and the threads resulting from knob unwinding (E). Confocal image stacks were recorded with a section spacing of $1 \mu \mathrm{m}$ and a projection of optical confocal sections is shown. Bars: $20 \mu \mathrm{m}(\mathbf{A})$ and $10 \mu \mathrm{m}(\mathbf{B})$

the nucleolus compartment which correspond to a tight cluster of non-expressing ribosomal genes (fig. 1B). Inside the nucleolus, chromatin has a diffuse appearance with no evidence for the presence of condensed chromatin foci (fig. 1B).

The 45S rDNA Chromatin Undergoes Decondensation after Exposure to Heat and Salinity Stress Factors

The organization of interphase ribosomal chromatin was evaluated after seed germination under specific abiotic stress conditions. Three-day-old seedlings were subjected either to cold $\left(4^{\circ} \mathrm{C}\right.$ for $\left.24 \mathrm{~h}\right)$ or heat $\left(42^{\circ} \mathrm{C}\right.$ for $\left.3 \mathrm{~h}\right)$. Another stress condition tested was germination under mild salinity $(150 \mathrm{mM} \mathrm{NaCl})$. We have analyzed the average number and the volume of heterochromatic knobs per cell (table 1). The number of knobs per cell is informative regarding any agglomeration or division of the knobs while the volume of knobs can be a better indicator for the correlation between chromatin conformation and the 

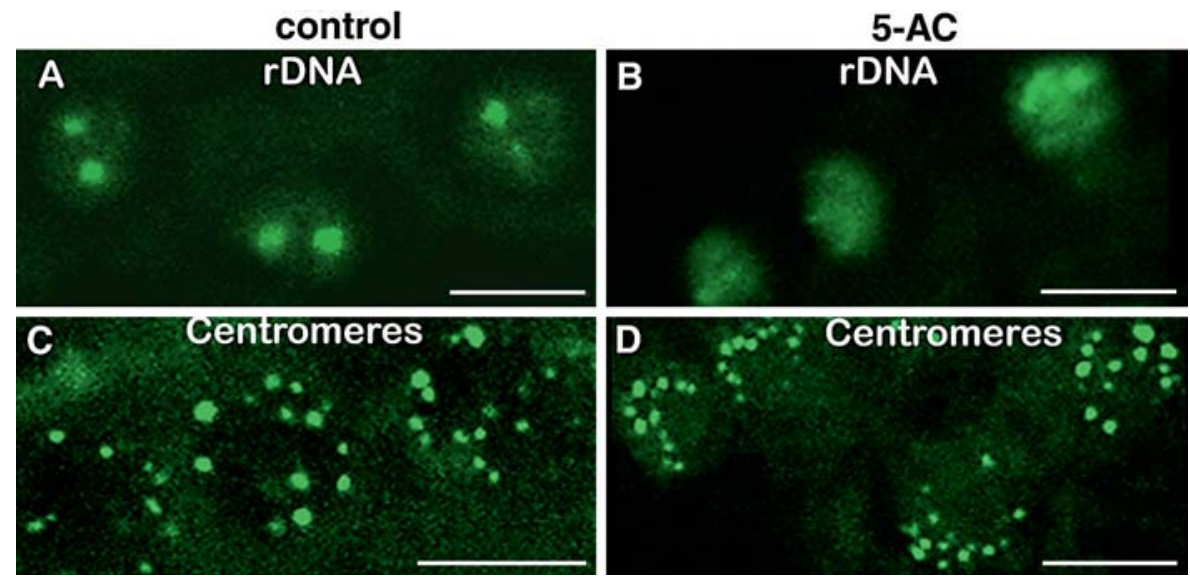

Fig. 2. 5-AC effects on rice chromatin organization: ribosomal chromatin (A, B) and centromeric chromatin (C, D). In A, 2 heterochromatic knobs are clearly seen. In $\mathbf{B}$, no clear heterochromatic knobs are identified presumably due to knob unwinding inside the nucleolus, which agrees with a strong signal of diffused chromatin observed overall the nucleolus. Centromeres are dis- persed circularly at the nucleus periphery (C). 5-AC is shown to induce centromere polarization at the nuclear periphery in one side of the nucleus (D). Confocal image stacks were recorded with a section spacing of $1 \mu \mathrm{m}$ and a projection of optical confocal sections is shown. Bar: $10 \mu \mathrm{m}$. fraction of genes being transcribed. The number of heterochromatic knobs around the nucleolus per cell was not statistically different between tested stress conditions and control (table 1). Regarding the volume of knobs, we observed significant differences between treatments (Kruskal-Wallis $\chi^{2}(4)=90.551 ; \mathrm{p}<0.001 ; \mathrm{n}=313$ ). The cold stress did not result in dramatic changes either of the morphological appearance or the number of heterochromatic knobs (fig. 1C, table 1) but the knobs' volume was increased although not statistically significantly (table 1). In contrast, after heat and salinity stress conditions, the heterochromatic knobs were smaller and lost their typical circular form (fig. 1D, E). Despite the commonality of effects of saline and heat on $45 \mathrm{~S}$ rDNA chromatin decondensation, the effect of salinity was more severe as a dispersed and complex conformation was observed (fig. 1E). After exposure to salt and heat stress factors, the volume of knobs decreased when compared to control (table 1).

\section{5-AC Causes Major Changes of Interphase Nuclear \\ Organization: It Greatly Increases Ribosomal \\ Chromatin Decondensation and It Induces \\ Centromere Polarization}

5-AC is widely known to induce DNA hypomethylation and here we show that it greatly affected rice ribosomal chromatin organization. Mostly, the knobs were no longer visible, and thus, not measurable in terms of volume. Instead a strong hybridization signal over the
Table 2. Distance ( \pm SD) between 5 S rDNA homologous loci and co-localization analysis between $5 \mathrm{~S}$ rDNA loci and centromeres in distinct abiotic stress conditions and in the presence of 5-AC

\begin{tabular}{llll}
\hline Treatment & $\begin{array}{l}\text { Cells } \\
\text { analyzed }\end{array}$ & $\begin{array}{l}\text { Distance between } \\
\text { 5S rDNA homologous } \\
\text { loci, } \mu \mathrm{m}\end{array}$ & $\begin{array}{l}\text { Co-localization } \\
5 \text { rDNA/ } \\
\text { centromeres }\end{array}$ \\
\hline Control & 50 & $2.8(0.67)$ & $37 \%$ \\
Cold & 50 & $2.6(0.80)$ & $36 \%$ \\
$\mathrm{Heat}$ & 50 & $3.6(1.02)$ & $44 \%$ \\
$\mathrm{NaCl}$ & 50 & $3.5(1.00)$ & $42 \%$ \\
5-AC & 50 & $4.08(1.14)$ & $55 \%$ \\
\hline
\end{tabular}

whole nucleolus indicated a dispersed and diffuse chromatin organization (fig. 2B).

FISH with a centromeric probe typically showed centromeres dispersed around the periphery of rice interphase nuclei (fig. 2C). Interestingly, seed germination on 5 -AC generated polarization of centromeres in $28 \%$ of the total interphase nuclei analyzed (fig. 2D). In contrast, the spatial arrangement of centromeres in interphase was not obviously perturbed by the abiotic stress factors tested (fig. 3). 
Spatial Disposition of $5 S$ rDNA in Rice Interphase

Nuclei Is Altered by Stress Exposure

FISH with the 5S rDNA probe revealed 2 discrete hybridization signals, relatively small, but clear, corresponding to each allele, localizing outside the nucleolus. The 5S rDNA FISH signal does not show obvious alterations with abiotic stresses or 5-AC (fig. 3). In interphase nuclei, both 5S rDNA and centromeres can co-localize and in this case there is clearly an overlapping of hybridization signals (e.g. fig. 3I). We analyzed the extent of colocalization between $5 \mathrm{~S}$ rDNA and centromeres and the distance between $5 \mathrm{~S}$ rDNA homologous loci after imposed abiotic stress and induced DNA hypomethylation (table 2). The frequency of co-localization between $5 \mathrm{~S}$ rDNA and centromeres was not completely independent of the treatment $\left(\chi^{2}(4)=4.927 ; \mathrm{p}=0.051 ; \mathrm{n}=100\right)$. The minimum co-localization rate was observed for the cold stress and control treatments while the higher rate of colocalization was observed when germination occurred in the presence of 5-AC (table 2). Regarding the distance between $5 \mathrm{~S}$ rDNA homologous loci, there were statistically significant differences between treatments (KruskalWallis $\left.\chi^{2}(4)=92.293 ; \mathrm{p}<0.001 ; \mathrm{n}=300\right)$. The distance between homologous loci was estimated at $2.8( \pm 0.67)$ $\mu \mathrm{m}$ and it was significantly increased to $3.6( \pm 1.02) \mu \mathrm{m}$ on heat and to $3.5( \pm 1.00) \mu \mathrm{m}$ on salinity stress factors. Seed germination on 5-AC also causes a notable increase in the distance between homologous $5 \mathrm{~S}$ rDNA loci, 4.081 $( \pm 1.14) \mu \mathrm{m}$, which is consistent with the widely described effects of this drug on chromatin decondensation. The cold stress caused a slight decrease in the distance of homologous 5S rDNA loci although this was not statistically significant.

\section{Discussion}

Explicit evidence of involvement of chromatin structural changes in plant response to stress is still lacking. The studies on ribosomal chromatin organization have been mainly focused on using FISH to determine the location of ribosomal genes on metaphase chromosomes. For example, in Oryza sativa ssp. japonica cv. Nipponbare (AA), the 45S rRNA genes are located at the end of the short arm of chromosome 9, while 5S rRNA genes are found on the short arm of chromosome 11, very close to the centromeric region [Shishido et al., 2000; Chung et al., 2008; Zhu et al., 2008]. We focused on the organization pattern of ribosomal chromatin in interphase nuclei from root tissue sections because transcription takes

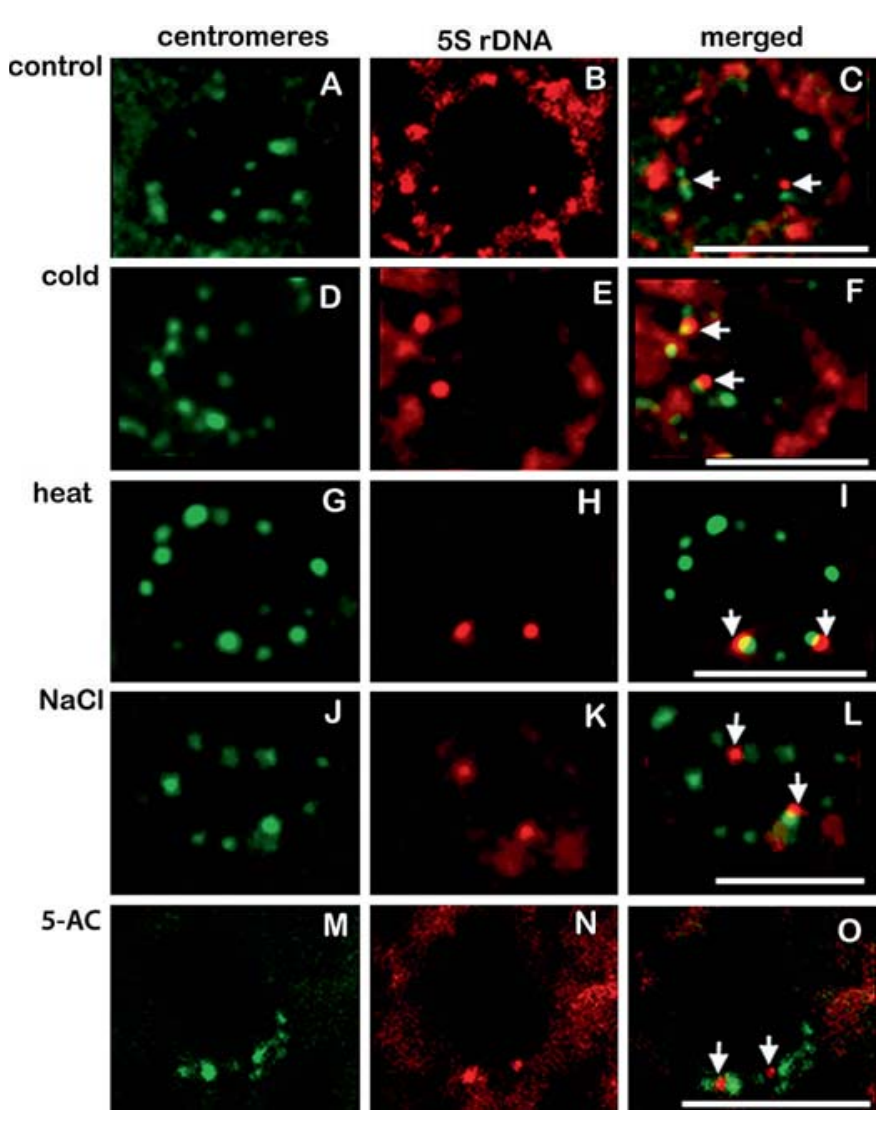

Fig. 3. Simultaneous labeling of centromeres (green) and 5S rDNA (red) in interphase nuclei of rice root sections is shown for distinct abiotic stress conditions and for 5-AC-induced DNA hypomethylation. A circular arrangement of centromeres is clearly shown on control (A) and in distinct abiotic stress conditions: cold (D), heat $(\mathbf{G})$ and $\mathrm{NaCl}(\mathbf{J})$. The circular arrangement of centromeres is affected by induced DNA hypomethylation through seed germination on 5-AC and the polarization of centromeres can be seen in one side of the nucleus (M). Regarding $5 \mathrm{~S}$ rDNA, 2 hybridization signals are clearly visible as small dots whose size and appearance are not altered by abiotic stresses or 5-AC (arrows in C, F, I, $\mathbf{L}, \mathbf{O}$ ). Merged images of both probes $5 \mathrm{~S}$ rDNA and centromeres, are also shown. The overlapping of $5 \mathrm{~S}$ rDNA alleles and centromeres can clearly be seen (e.g. I). Confocal image stacks were recorded with a section spacing of $1 \mu \mathrm{m}$ and a projection of 2 confocal sections is shown. Bar: $10 \mu \mathrm{m}$.

place during interphase. Firstly, we have shown that the organization pattern of $45 \mathrm{~S}$ rDNA chromatin in rice interphase nuclei consists of 2 circular heterochromatic knobs at the periphery of the nucleolus. Inside the nucleolus, chromatin exhibits a diffuse pattern without any sign of small knobs of condensed ribosomal chromatin foci. Contrastingly, in wheat, perinucleolar knobs unwind, generating several smaller heterochromatic foci 
remaining inside the nucleolus [Silva et al., 2008]. Previous unpublished experiments in wheat seedlings submitted to a heat shock of $42^{\circ} \mathrm{C}$ for $2 \mathrm{~h}$ caused drastic alterations in ribosomal chromatin organization in wheat interphase nuclei; the heterochromatic knobs are absent due to its decondensation and subsequently fibers are seen inside the nucleolus (online suppl. fig. 1, www. karger.com/doi/10.1159/000322287). In the present work, we show that heat and salinity stress exposures are both associated with a decondensation of $45 \mathrm{~S}$ rDNA chromatin as indicated by the decrease in the volume of heterochromatin knobs. The effect of saline treatment on rDNA chromatin decondensation is considerably more severe than heat stress. This may well be due to a higher sensitivity of rice for salinity stress particularly during the germination stage. Indeed, there are studies at the ultrastructural level on rice and onion cells under salt treatment showing dramatic damages of nuclear chromatin organization [Rahman et al., 2000; Bennici and Corrado, 2009]. In yeast, environmental stress or nutritional deprivation was also shown to cause changes in the ratio of accessible vs. inaccessible rDNA chromatin [Conconi et al., 1989; Sandmeier et al., 2002]. On the other hand, the exposure to cold stress did not dramatically affect $45 \mathrm{~S}$ rDNA chromatin organization. For instance, 2 heterochromatin perinucleolar knobs were seen with a statistically insignificant change in volume. This is not surprising, since cold treatment is often associated with slowing down of metabolism, and it is widely used as a metaphase arresting agent based on its effects on chromatin condensation [Schwarzacher and Heslop-Harrison, 2000].

There are several reports in the literature providing a link between environmental stresses, DNA methylation changes and regulation of stress-responsive gene expression. For example, in tobacco plants, aluminium, salt, cold, and oxidative stresses were shown to induce transcription and DNA demethylation of a gene encoding a glycerophosphodiesterase-like protein [Wada et al., 2004; Choi and Sano, 2007]. Moreover, studies on plant hybrids (e.g. wheat/rye) have shown that epigenetics is involved in the silencing of a set of parental rDNA clusters [Preuss and Pikaard, 2007]. Stress-induced demethylation may relax chromatin structure, thereby allowing enhanced transcription [Shilatifard, 2006]. Thus, we sought to experimentally mimic DNA hypomethylation, referred to in the literature as being associated with abiotic stress exposure. To do this, we used 5-AC, which has been shown to induce chromosome decondensation, transgene repositioning and in- creased gene expression during interphase [Santos et al., 2002]. Here, we showed that 5-AC causes extensive decondensation of $45 \mathrm{~S}$ rDNA chromatin in interphase nuclei. The nucleoli acquired a 'painted appearance' resulting from decondensation of heterochromatic knobs and thus are no longer visible.

In wheat, centromeres are polarized at one side of the interphase nucleus showing a Rabl configuration [Abranches et al., 1998]. The polarized centromeric disposition in wheat interphase nuclei was not significantly disturbed by induced DNA hypomethylation through germination on a 5-AC solution [Santos et al., 2002]. In contrast, FISH with a centromeric probe clearly showed that there was no Rabl configuration in rice interphase nuclei (except in xylem vessel precursor cells), with the centromeres evenly distributed around the nuclear periphery [Prieto et al., 2004; Santos et al., 2004]. Here, we show that 5 -AC induces centromere polarization in some rice interphase nuclei (28\%). There is no convincing explanation for the presence or absence of a Rabl configuration in plants. Also, we cannot find a good argument for rice centromere polarization after 5-AC induced DNA hypomethylation. It may well be possible that with the genome hypomethylated and the chromatin very decondensed and presumably flexible, the normal chromosome structures and forces that move chromosomes away from the Rabl configuration at the end of telophase do not operate. Effectively, the centromeres could stay in their telophase positions and other parts of the chromosome could relocate without pulling the centromeres away. Previous studies showed that multiple homologous transgene loci located at a number of sites along a chromosome arm could associate in the interphase nuclei of wheat [Abranches et al., 2000], but the treatment with 5-AC reduced the association between transgene loci [Santos et al., 2002]. Agreeing with a higher global chromatin flexibility associated with DNA hypomethylation, we observed an increase in the distance between homologous $5 \mathrm{~S}$ rDNA loci. Puzzlingly, it is not clear whether in plants centromeric chromatin can act as domains for gene silencing as has been shown in animals [Merkenschlager et al., 2004]. In rice, the presence of active genes in the functional domains of several centromeres has been reported [Nagaki et al., 2004]. We observed a higher percentage of co-localization between $5 \mathrm{~S}$ rDNA and centromeres in 5-AC experiments as well as upon heat and salinity stress which we found to be associated with $45 \mathrm{~S}$ rDNA decondensation. We cannot find a good explanation for that, but one possibility is that rice centromeres are not domains for gene silencing as has been shown to occur in 
animals. In the present work, we describe inducible changes on heterochromatic domains (45S, $5 \mathrm{~S}$ rDNA loci and centromeres) of the rice genome. However, it should be expected that other genome-wide changes associated with stress exposure, e.g. of an epigenetic nature, need further investigation since it can help to understand the huge plant plasticity responses to challenging environmental conditions.

\section{Acknowledgements}

We thank Peter Shaw and Pablo Gonzalez for revising the manuscript and for helpful suggestions and comments. We also thank Professors N. Ohmido and J. Jiang for kindly providing plasmids pRTY5S and pRCS2, respectively. A.P.S. and L.F. are funded by Fundação para a Ciência e Tecnologia (FCT), Portugal. This work was supported by the project 'Chromatin remodelling and abiotic stress responses in rice' Fundação para a Ciência e a Tecnologia PTDC/BIA-BCM/64215/2006.

\section{References}

-Abranches R, Beven AF, Aragón-Alcaide L, Gonzalez-Melendi P, Wells B, Beven A, Shaw PJ: Shaw PJ: Transcription sites are not correlated with chromosome territories in wheat nuclei. J Cell Biol 143:5-12 (1998).

-Abranches R, Santos AP, Wegel E, Williams S, Castilho A, et al: Widely-separated multiple transgene integration sites in wheat chromosomes are brought together at interphase. Plant J 24:713-723 (2000).

-Amasino R: Vernalization, competence, and the epigenetic memory of winter. Plant Cell 16: 2553-2559 (2004).

-Arnholdt-Schmitt B: Stress-induced cell reprogramming: a role for global genome regulation? Plant Physiol 136:2579-2586 (2004).

Bastow R, Mylne J, Lister C, Lippman Z, Martiennsen R, Dean C: Vernalization requires epigenetic silencing of FLC by histone methylation. Nature 427:164-167 (2004).

Bennici A, Corrado T: Ultrastructural effects of salinity in Nicotiana bigelovii var. bigelovii callus cells and Allium cepa roots. Caryologia 62:124-133 (2009).

-Chinnusamy V, Zhu JK: Epigenetic regulation of stress responses in plants. Curr Opin Plant Biol 12:133-139 (2009).

-Choi CS, Sano H: Abiotic-stress induces demethylation and transcriptional activation of a gene encoding a glycerophosphodiesterase-like protein in tobacco plants. Mol Genet Genome 277:589-600 (2007).

-Chung MC, Lee Y, Cheng YY, Chou YJ, Lu CF: Chromosomal polymorphism of ribosomal genes in the genus Oryza. Theor Appl Genet 116:745-753 (2008).

Conconi A, Widmer RM, Koller T, Sogo JM: Two different chromatin structures coexist in ribosomal RNA genes throughout the cell cycle. Cell 57:753-761 (1989).

Dong F, Jiang J: Non-Rabl patterns of centromere and telomere distribution in the interphase nuclei of plant cells. Chromosome Res 6:551558 (1998).
Single ribosomal transcription units are linear compacted Christmas trees in plant nucleoli. Plant J 27:223-233 (2001).

Huang S, Rothblum LI, Chen D: Ribosomal chromatin organization. Biochem Cell Biol 84:444-449 (2006).

Kim JM, To TK, Nishioka T, Seki M: Chromatin regulation functions in plant abiotic stress responses. Plant Cell Environ 33:604-611 (2010).

Madlung A, Comai L: The effect of stress on genome regulation and structure. Ann Bot 94: 481-495 (2004).

McClintock B: The significance of responses of the genome to challenge. Science 226:792801 (1984).

McKeown PC, Shaw PJ: Chromatin: linking structure and function in the nucleolus. Chromosoma 118:11-23 (2009).

Merkenschlager M, Amoils S, Roldan E, Rahemtulla A, O'Connor E, et al: Centromeric repositioning of coreceptor loci predicts their stable silencing and the CD4/CD8 lineage choice. J Exp Med 200:1437-1444 (2004).

Nagaki K, Cheng Z, Ouyang S, Talbert PB, Kim $M$, et al: Sequencing of a rice centromere uncovers active genes. Nat Genet 36:138-145 (2004).

Preuss S, Pikaard CS: rRNA gene silencing and nucleolar dominance: insights into a chromosome-scale epigenetic on/off switch. Biochim Biophys Acta 1769:383-392 (2007).

- Prieto P, Santos AP, Moore G, Shaw P: Chromosomes associate premeiotically and in xylem vessel cells via their telomeres and centromeres in diploid rice (Oryza sativa). Chromosoma 112:300-307 (2004).

-Rahman MS, Matsumuro T, Miyake H, Takeoka Y: Salinity induced ultrastructural alterations in leaf cells of rice (Oryza sativa L.). Plant Prod Sci 3:422-429 (2000).

-Sandmeier JJ, French S, Osheim Y, Cheung WL, Gallo CM, et al: RPD3 is required for the inactivation of yeast ribosomal DNA genes in stationary phase. EMBO J 21:4959-4968 (2002).
-Santos AP, Shaw P: Interphase chromosomes and the Rabl configuration: does genome size matter? J Microsc 214:201-206 (2004).

-Santos AP, Abranches R, Alison E, Stoger E, Viegas W, Shaw PJ: The architecture of interphase chromosomes and gene positioning are altered by changes in DNA methylation and histone acetylation. J Cell Sci 115:45974606 (2002).

Schwarzacher T, Heslop-Harrison JS: Practical in situ Hybridization. (Bios, Oxford 2000).

-Shilatiford A: Chromatin modifications by methylation and ubiquitination: implications in the regulation of gene expression. Annu Rev Biochem 75:243-269 (2006).

-Shishido R, Sano Y, Fukui K: Ribosomal DNAs: an exception to the conservation of gene order in rice genomes. Mol Gen Genet 263: 586-591 (2000).

-Silva M, Pereira HS, Bento M, Santos AP, Shaw $\mathrm{P}$, et al: Interplay of ribosomal DNA loci in nucleolar dominance: dominant NORs are up-regulated by chromatin dynamics in the wheat-rye system. PLoS ONE 3:e3824 (2008).

Tessadori F, Schulkes RK, Driel R, Fransz P: Light-regulated large scale reorganization of chromatin during the floral transition in Arabidopsis. Plant J 50:848-857 (2007).

-Wada Y, Miyamoto K, Kusano T, Sano H: Association between up-regulation of stress-responsive genes and hypomethylation of genomic DNA in tobacco plants. Mol Genet Genomics 271:658-666 (2004).

Zhu XY, Cai DT, Ding Y: Molecular and cytological characterization of $5 \mathrm{~S}$ rDNA in Oryza species: genomic organization and phylogenetic implications. Genome 51:332-340 (2008).

\section{(C) Free Author Copy - for personal use only}

\section{ANY DISTRIBUTION OF THIS ARTICLE WITHOUT WRITTEN CONSENT FROM S. KARGER AG, BASEL IS A VIOLATION OF THE COPYRIGHT.}

Written permission to distribute the PDF will be granted against payment of a permission fee, which is based on the number of accesses required. Please contact permission@karger.ch 